\title{
Beyond the usual cognitive suspects: The importance of speechreading and audiovisual temporal sensitivity in reading ability
}

\author{
Ana A. Francisco a,*, Margriet A. Groen ${ }^{b}$, Alexandra Jesse ${ }^{c}$, James M. McQueen d,e \\ a Behavioural Science Institute, Radboud University, Postbus 9104, 6500 HE Nijmegen, The Netherlands \\ b Behavioural Science Institute, Radboud University, Nijmegen, The Netherlands \\ c Department of Psychological and Brain Sciences, University of Massachusetts, USA \\ d Donders Institute for Brain, Cognition and Behaviour, Radboud University, Nijmegen, The Netherlands \\ e Max Planck Institute for Psycholinguistics, Nijmegen, The Netherlands
}

\section{A R T I C L E I N F O}

\section{Article history:}

Received 21 January 2016

Received in revised form 2 December 2016

Accepted 5 January 2017

Available online xxxx

\section{Keywords:}

Reading

Dyslexia

Audiovisual temporal sensitivity

Speechreading

Individual differences

\begin{abstract}
A B S T R A C T
The aim of this study was to clarify whether audiovisual processing accounted for variance in reading and reading-related abilities, beyond the effect of a set of measures typically associated with individual differences in both reading and audiovisual processing. Testing adults with and without a diagnosis of dyslexia, we showed that-across all participants, and after accounting for variance in cognitive abilities-audiovisual temporal sensitivity contributed uniquely to variance in reading errors. This is consistent with previous studies demonstrating an audiovisual deficit in dyslexia. Additionally, we showed that speechreading (identification of speech based on visual cues from the talking face alone) was a unique contributor to variance in phonological awareness in dyslexic readers only: those who scored higher on speechreading, scored lower on phonological awareness. This suggests a greater reliance on visual speech as a compensatory mechanism when processing auditory speech is problematic. A secondary aim of this study was to better understand the nature of dyslexia. The finding that a sub-group of dyslexic readers scored low on phonological awareness and high on speechreading is consistent with a hybrid perspective of dyslexia: There are multiple possible pathways to reading impairment, which may translate into multiple profiles of dyslexia.
\end{abstract}

(c) 2017 Elsevier Inc. All rights reserved.

\section{Introduction}

Developmental dyslexia (henceforth dyslexia) is a learning disorder characterized by severe difficulties in attaining an adequate reading level, despite normal intelligence and educational opportunities and in the absence of any sensory or neurological impairment (Lyon, Shaywitz, \& Shaywitz, 2003). Since reading is an audiovisual process that requires learning and the automatization of systematic links between graphemes and phonemes, it is possible that reading impairment in dyslexia reflects an audiovisual processing deficit (see, for a review of the literature, Hahn, Foxe, \& Molholm, 2014). In the present study, we tested this hypothesis by asking whether individual differences in audiovisual temporal sensitivity and in speechreading account for individual differences in reading and reading-related abilities among adult readers with and without diagnosed dyslexia, above and beyond other cognitive skills typically associated with reading. Looking into individual differences among readers with and without dyslexia also allowed us

\footnotetext{
* Corresponding author.

E-mail addresses: claraafrancisco@gmail.com (A.A. Francisco), m.groen@pwo.ru.nl (M.A. Groen), ajesse@psych.umass.edu (A. Jesse), j.mcqueen@donders.ru.nl (J.M. McQueen).
}

to contribute to another debate on the nature of dyslexia: Is dyslexia better explained by single or multiple deficit models?

Dyslexia represents a persistent condition rather than a transient developmental lag associated with the beginning of reading acquisition. In addition to manifest reading difficulties (e.g., Elbro, Nielsen, \& Petersen, 1994), adults with dyslexia also show impaired phonological processing (e.g., Vellutino, Fletcher, Snowling, \& Scanlon, 2004). Phonological awareness (the ability to perceive and manipulate the sound structure of spoken words) and letter naming (how quickly letters can be named) are two reading-related abilities that rely on phonological processing. Both abilities are impaired in adult dyslexic readers (e.g. Bekebrede, van der Leij, Plakas, Share, \& Morfidi, 2010; Elbro et al., 1994; van Bergen, de Jong, Maassen, \& van der Leij, 2014), leading many to believe that a phonological deficit underlies dyslexia (e.g., Snowling, 2000; Stanovich, 1988). Phonological awareness is fundamental for the learning and storing of mappings between visual symbols (graphemes) and letter sounds (phonemes) (Melby-Lervåg, Lyster, \& Hulme, 2012). Hence, it has been described as the primary predictor of reading success (Bast \& Reitsma, 1998; Caravolas, 2004; Høien, Lundberg, Stanovich, \& Bjaalid, 1995; Melby-Lervåg et al., 2012; Müller \& Brady, 2001; Öney \& Durgunoğlu, 1997; Snowling, 2000; Stanovich \& Siegel, 1994; Vellutino et al., 2004, Wimmer, Landerl, Linortner, \& 
Hummer, 1991). Letter naming is hypothesized to reflect the ease of access to and retrieval of phonological codes for letters from long-term memory in children (e.g. Chiappe, Stringer, Siegel, \& Stanovich, 2002; Pennington, Cardoso-Martins, Green, \& Lefly, 2001; Schatschneider, Carlson, Francis, Foorman, \& Fletcher, 2002; Torgesen, Wagner, \& Rashotte, 1994), adolescents (Pennington et al., 2001), and adults (Chiappe et al., 2002). It is an important predictor of reading fluency and dyslexia in alphabetic scripts in children (e.g., van den Bos, 1998; de Jong \& van der Leij, 1999; de Jong \& van der Leij, 2002; Kirby, Parrila, \& Pfeiffer, 2003Georgiou, Parrila, Kirby, \& Stephenson, 2008; Kirby, Desrochers, Roth, \& Lai, 2008) and adults (Jones, Branigan, \& Kelly, 2009).

In summary, adult dyslexic readers show difficulties not only in reading, but also in reading-related abilities, such as phonological awareness and letter naming. This wider reading profile has value in diagnosing individuals with dyslexia (e.g., Reynolds \& Shaywitz, 2009). Moreover, adult dyslexic readers might have developed strategies to compensate for their difficulties in reading. Thus, they might not differ from typical readers in reading measures, but, when faced with tasks such as those measuring phonological awareness and letter naming, residual difficulties might become apparent. Hence, in this study, we assessed the associations of audiovisual processing with reading ability, but also with other reading-related abilities reflecting a phonological deficit in dyslexia (that is, phonological awareness and letter naming).

As mentioned before, reading impairment might reflect a deficit in audiovisual processing and, indeed, children and adult dyslexic readers have been shown to inadequately process audiovisual objects, for instance, while being presented with audiovisual and unisensory letters and speech sounds (Blau, van Atteveldt, Ekkebus, Goebel, \& Blomert, 2009; Blau et al., 2010; Froyen, Willems, \& Blomert, 2011; Kast, Bezzola, Jäncke, \& Meyer, 2011; Kronschnabel, Brem, Maurer, \& Brandeis, 2014; Mittag, Thesleff, Laasonen, \& Kujala, 2013), while identifying unisensory and audiovisual speech (e.g., Hayes, Tiippana, Nicol, Sams, \& Kraus, 2003), and while matching non-linguistic audiovisual materials (e.g., rectangles and tones, Widmann, Schröger, Tervaniemi, Pakarinen, \& Kujala, 2012). For a subset of the sample of participants tested in this study, we have recently shown differences between dyslexic and typical adult readers in their audiovisual temporal sensitivity (Francisco, Jesse, Groen, \& McQueen, 2017). Adult typical and dyslexic readers performed a simultaneity judgment task, in which participants had to indicate whether or not auditory and visual components of speech and non-speech stimuli presented with different stimulus onset asynchronies (SOAs) occurred simultaneously. The speech stimuli elicited the McGurk effect (McGurk \& MacDonald, 1976), a perceptual illusion that is characterized by the joint interpretation of incongruent auditory and visual speech. For example, when hearing the syllable / apa/ while seeing a speaker pronouncing /aka/, participants often report perceiving /ata/ - referred to as a fusion response. Using McGurk stimuli provides at least two advantages. First, it allows one to analyze different measures: Proportion of fusion responses, proportion of auditorybased responses, and proportion of visually-based responses. Second (if using different SOAs), it allows one to test whether temporal sensitivity judgments have consequences for identification (given that a congruent stimulus, in contrast, will almost always be identified in the same way). The non-speech stimuli used in our study showed a woman clapping her hands. We showed that adult dyslexic readers had a wider time window of perceived audiovisual synchrony than typical readers, for both speech and non-speech stimuli, that is, they judged asynchronous events as being in-synchrony more often than typical readers.

These results on the perceived simultaneity of audiovisual speech events were in line with those of other studies reporting dyslexic adults' extended temporal windows when judging the temporal order of audiotactile, visuotactile, and audiovisual events compared to typical readers (Hairston, Burdette, Flowers, Wood, \& Wallace, 2005; Laasonen et al., 2002). We and others (Hairston et al., 2005; Wallace \& Stevenson, 2014) have argued that such an expanded time window could result in difficulties in processes that are dependent on the rapid and accurate integration of cues from multiple senses, such as reading (see Froyen, Van Atteveldt, Bonte, \& Blomert, 2008). Expanding the temporal window over which auditory and visual events are seen as synchronous could result in inappropriate grapheme-phoneme correspondences and, consequently, in less efficient decoding. Moreover, it might lead to substantial difficulties in the construction of strong reading representations, in that the wider windows will lead to greater ambiguity in the correspondences between the auditory and the visual elements of a word (Hairston et al., 2005; Wallace \& Stevenson, 2014).

Even though these studies provide evidence for an audiovisual deficit in dyslexia, the nature of the relationship between audiovisual processing and reading remains mostly unknown. Studying individual differences could help clarify this relationship. For instance, in an event-related potential (ERP) study testing typical, reading impaired and severely reading impaired children, Žarić et al. (2014) found that individual differences in ERP measures of letter-speech sound integration correlated with reading fluency, suggesting that early audiovisual speech integration processes scale with individual differences in reading ability. Gullick and Booth (2014) investigated the relationship of behavioral performance and brain function related to phonemegrapheme integration with connectivity in the arcuate fasciculus. In a range of children with different reading abilities, they showed that both response accuracy and brain activity for audiovisual rhyme judgments were predictive of fractional anisotropy along the arcuate fasciculus. Fractional anisotropy reflects the degree of directional diffusivity of white matter voxels. Higher values are taken to reflect greater connectivity between brain regions and thus more efficient processing of information along a specific tract. These studies stress the importance of considering individual differences in reading, reading-related abilities associated with phonological processing, and audiovisual processing in order to understand how reading ability and audiovisual processing are related.

In the present study, we aimed to test whether individual differences in audiovisual processing account for variance in reading, and in reading-related abilities tapping into phonological processing. Individual differences in reading and reading-related abilities have been described in dyslexic adult readers (e.g., Ramus et al., 2003; Rosen, 2003). Such differences may be due to individual differences in distinct cognitive processes. Therefore, to pinpoint the nature of the contribution of audiovisual processing to reading, the effect of cognitive abilities typically associated with reading also ought to be considered. Since the ability to learn to read depends on the acquisition of a variety of different types of knowledge and skills (c.f. Vellutino et al., 2004), we selected a set of distinct cognitive abilities typically associated in the literature with reading ability. First, working memory has been consistently associated with reading, at least in children (Christopher et al., 2012; Swanson, Howard, \& Saez, 2006; Swanson, Zheng, \& Jerman, 2009) and adolescents (Christopher et al., 2012). It has a fundamental role in: a) establishing stable associations between lexical and sublexical components of spoken and printed words; and b) encoding, storing, and retrieving the different types of information entailed in learning to read (Vellutino et al., 2004). Second, inhibitory control may be related to reading in adults, as it impacts working memory and its contents (Hasher, Zacks, \& May, 1999). It ensures that information in the memory buffer is restricted to goal-relevant information, for instance, by preventing any activated but goal-irrelevant information from entering working memory. In a large-sample study, reading-impaired children and adult readers were shown to have greater difficulty in preventing irrelevant information from entering working memory (Chiappe, Siegel, \& Hasher, 2000). Third, processing speed is also typically associated with reading. Dyslexic adult readers (Breznitz \& Meyler, 2003; Laasonen, Lahti-Nuuttila, \& Virsu, 2002; Stoodley \& Stein, 2006; Wolf, Bowers, \& Biddle, 2000) and children (Pennington \& Bishop, 2009; Wolf et al., 2000) show slower processing speed than typical readers across a range of tasks both in the visual and in the auditory modality. 
Recently, linguistic and non-linguistic processing speed has been argued to be a more powerful predictor of reading than even phonological awareness, at least in dyslexic children (Park \& Lombardino, 2013). Fourth, children with reading impairment have also been shown to perform poorly in paired-associate learning tasks (e.g., Vellutino, Scanlon, \& Spearing, 1995; Mayringer \& Wimmer, 2000; Messbauer \& de Jong, 2003). Furthermore, visual-verbal paired associate learning has been reported to be a unique predictor of visual word recognition, after controlling for phoneme awareness and verbal-verbal paired associate learning, at least in children (Hulme, Goetz, Gooch, Adams, \& Snowling, 2007). Finally, successful reading also depends on a certain level of cognitive flexibility. For instance, while reading, an individual may need to generate and evaluate several possibilities for the pronunciation of a word, before selecting the most adequate one for a given context (Gaskins, 2008). Increased cognitive flexibility has been argued to strengthen the effectiveness of phoneme awareness and of reading and spelling instruction for kindergarten and first-grade students (Krause \& Moore, 1997).

Individual differences have been reported not only in reading, but also in audiovisual processing. In the general adult population, there have been reports of individual differences in the size of the temporal window during which events are perceived as synchronous (Conrey \& Pisoni, 2006; Miller \& D'Esposito, 2005; Stevenson, Zemtsov, \& Wallace, 2012), in the size of the audiovisual benefit (obtained when bimodal rather than unimodal events are presented) (e.g., Jesse, Vrignaud, Cohen, \& Massaro, 2000; MacLeod \& Summerfield, 1987), and in the perception of the McGurk effect (e.g., Nath \& Beauchamp, 2012; Strand, Cooperman, Rowe, \& Simenstad, 2014). Such variability could at least partially be accounted for by differences in speechreading (the ability to identify speech based only on seeing the speaker's talking face). Speechreading is a fundamental component of audiovisual processing, with better adult speechreaders showing a larger audiovisual benefit (e.g., Jesse \& Janse, 2012). Additionally, speechreading ability has been found to be a strong correlate of reading ability in both deaf and hearing children (Kyle \& Harris, 2010). Woll (2012) argued that the information derived through speechreading supports the development of the phonological skills needed for reading. Speechreading is itself characterized by substantial individual variability (e.g., Summerfield, 1992), and though some authors have attempted to clarify this variability, little is known about which factors underlie individual differences in speechreading. Working memory (Feld \& Sommers, 2009; Lyxell \& Rönnberg, 1989, 1993) and processing speed (Feld \& Sommers, 2009) seem to be important components of speechreading in both younger and older adults.

In summary, individual differences have been observed both in reading and in audiovisual processing. Importantly, some of the cognitive measures related to reading ability, have also been associated with audiovisual processing. This needs to be considered when the aim is to understand the unique contribution of audiovisual processing in reading ability.

Focusing on individual differences will also allow us to contribute to the clarification of another aspect of the nature of dyslexia. Among the debates in dyslexia (see, for instance, Ramus, 2003), one unresolved issue is the question of whether dyslexia is explained better by single (e.g. Ramus et al., 2003) or multiple deficit (e.g. Bishop \& Snowling, 2004; Pennington, 2006) models. While single deficit models assume that a single deficit is necessary and sufficient to impair reading performance, multiple deficit models argue that a single deficit is necessary but not sufficient (i.e., there must be at least two deficits). Pennington et al. (2012) proposes an alternative to single and multiple deficit models: a hybrid perspective that assumes the existence of multiple cognitive profiles among dyslexic readers. Moreover, it assumes that the relationship between cognitive deficits and dyslexia is probabilistic, rather than deterministic. Looking at individual differences could allow us to understand whether there are sub-groups with different reading and/or cognitive profiles within the dyslexic group and thus contribute to the debate on the type of model that better explains dyslexia.

In summary, in the present study, we tested whether audiovisual processing, in particular, speechreading, audiovisual speech identification, and audiovisual temporal sensitivity, could account for variance in reading and reading-related abilities (phonological awareness and letter naming), above and beyond the variance explained by a set of cognitive abilities typically associated with reading. Reading performance (errors and time), phonological awareness, and letter naming were assessed in a sample of typical and dyslexic adult readers. To assess audiovisual processing, the same participants performed a simultaneity judgment task with speech (McGurk) and non-speech (clapping) stimuli with different SOAs and a speech identification task, again using the same McGurk stimulus with different SOAs. To evaluate the unique contribution of audiovisual processing in reading and reading-related measures, those participants were also tested in a set of tasks assessing the cognitive abilities typically associated with reading: verbal working memory, inhibitory control, processing speed, paired-associate learning, and cognitive flexibility. We believe that this approach could contribute to a better understanding of the nature of dyslexia, a secondary aim of the present study.

\section{Method}

\subsection{Participants}

One-hundred-and-fourteen native Dutch speakers - of which 60 had received a clinical diagnosis of dyslexia during childhood - were recruited via the Radboud University SONA system. All participants were students at the Radboud University or at the HAN University of Applied Sciences in Nijmegen and received a monetary compensation or course credits for their participation in the study.

In addition to having normal or corrected-to-normal vision, participants had to pass a standard audiometric hearing screening ( $<30 \mathrm{~dB}$ at $125,250,500,1 \mathrm{~K}, 2 \mathrm{~K}, 3 \mathrm{~K}$, and $4 \mathrm{KHz}$ in both ears). Nine participants (seven with a diagnosis of dyslexia) did not pass this screening and were therefore excluded, leaving 53 participants with a diagnosis of dyslexia ( 11 males; age: $M=22.62, S D=2.68$ years old) and 52 participants without such a diagnosis (13 males; age: $M=22.08, S D=$ 2.72 years old). Thirty-nine of the typical readers and 51 of the dyslexic readers had also been included in a group differences analysis, reported in Francisco et al. (2017).

All participants gave written informed consent prior to the experiment.

\subsection{Reading and reading-related tasks}

\subsubsection{Reading}

A text-reading task from a standardized Dutch reading and writing battery for the diagnosis of dyslexia in adolescents and adults [GlEschr Test voor gevorderd Lezen en Schrijven (De Pessemier \& Andries, 2009)] was used to assess reading ability. The 582-word text consisted of three paragraphs increasing in difficulty. Text difficulty scores (Flesch Reading Ease Scores, Flesch, 1948) for the first, second, and third paragraph were 59.7, 39.8, and 8.0, respectively. Participants were instructed to read the text out loud, and it was emphasized that reading the text clearly and accurately was more important than reading it quickly. Silent pre-reading of the text was not allowed. In case a participant took more than five seconds to read a word, the experimenter would read that word out loud and ask the participant to continue by reading the next word. Both the time taken to read the text (reading time in seconds) and the total number of substantial errors (omissions, additions, replacements, and inversions; reading errors) were measured. In order to check whether typical and dyslexic readers made different types of reading errors, chisquare tests of independence were conducted on reading errors. No relationships were found between reading group and types of errors 
committed: Omissions, $\chi^{2}(35)=38.67, p=0.31$; additions, $\chi^{2}(46)=$ 52.16, $p=0.25$; replacements, $\chi^{2}(38)=43.18, p=0.26$; inversions, $\chi^{2}$ $(13)=17.04, p=0.2$. As indicated in the manual, the reading task presents good indices of internal consistency both for number of substantial errors (Guttman split-half $=0.77$ ) and for time taken to complete the task (Guttman split-half $=0.90$ ).

\subsubsection{Phonological awareness}

Phonological awareness was assessed with the reversal task from the Gl\&schr (De Pessemier \& Andries, 2009). During this task, participants heard pairs of pre-recorded items and were asked to indicate by giving a yes/no answer whether the second token heard in a pair was the phonological reverse of the first one (e.g., gak would be the phonological reverse of $\mathrm{kag}$ ). Participants were not allowed to write down the heard items, and were instructed to answer as quickly as possible. Six practice items, during which feedback was given, preceded 20 experimental items, during which no feedback was given. Time (in seconds) to complete the task and the number of correct responses were measured and combined into a phonological awareness total score, using the formula provided in the manual [(time/accuracy) $\times 10$ ]. For this total measure, higher scores reflected worse performance. As indicated in the manual, reliability of this task had been calculated at $r=0.90$ (Guttman split-half reliability).

\subsubsection{Letter naming}

A subtask from the Gl\&schr (De Pessemier \& Andries, 2009) was used to assess letter naming. Twenty-two different letters were used in this discrete task. The letters were presented either once $(a, c, d, j$, $\mathrm{o}, \mathrm{r}, \mathrm{u}, \mathrm{v}, \mathrm{w}, \mathrm{x}$ ), twice (b, g, h, i, m, n, p, s, t, z) or three times (f, k). The participants saw one letter at a time in the center of the screen. Their task was to name the letter as quickly as possible and continue by pressing a button. The order of presentation of the letters followed the prescribed order in the manual and was the same for all participants. Time (time taken, in seconds, to complete the task) was measured. As indicated in the manual, this subtask has adequate levels of test-retest reliability (0.76) (De Pessemier \& Andries, 2009).

\subsection{Cognitive tasks}

\subsubsection{Verbal working memory}

Verbal working memory was assessed with the digit-span subtest of the Wechsler Adult Intelligence Scale (WAIS-IV-NL; Wechsler, 2012). Both forms of the subtest (forward and backward) were used. In the forward form, sequences of numbers were read out loud and the participant was asked to repeat them in the same order. This form consisted of eight items (with two digit sets each), ranging from two to nine in length. The items could be assigned zero, one, or two points. The participant received two points when both digit sets were correctly repeated, one point when only one of the digit sets was correctly produced and zero points when both digit sets were incorrect. The task was stopped when two incorrect answers were given for an item. In the backward form, the procedure was identical, with the exception that participants were asked to repeat the set of heard numbers in reverse order. This form consisted of seven items (with two digit sets each). The number of correct answers within each form was computed. Both totals were then summed ( $\max .=30$ ) and used to compute a standardized score using the formula in the manual $(M=10, S D=3)$. This subtest has a split-half reliability of 0.91 (Pearson, 2012).

\subsubsection{Inhibitory control}

Inhibitory control was measured using the Simon task (Simon, 1990). In this computerized task, subjects viewed a colored square in either their left or in their right visual field. When a green square was presented, a button left of the midline had to be pressed; when the square was red, a button right of the midline had to be pressed. On congruent trials (60 trials), the square was presented on the same side as the response had to be made (e.g., a green square presented on the left side). On incongruent trials (60 trials), the square was presented on the opposite side from the response (e.g., a green square presented on the right side). The Simon effect, defined as the average of the reaction times in the incongruent trials minus the average of the reaction times in the congruent trials, is the outcome measure that will be reported. The Simon Task has reliability coefficients ranging from 0.56 to 0.65 (Borgmann, Risko, Stolz, \& Besner, 2007).

\subsubsection{Processing speed}

Digit-symbol substitution, a subtest of the WAIS-IV-NL (Wechsler, 2012), was used to assess processing speed. The test consisted of nine digit-symbol pairs followed by a list of digits. After completing a 7item practice block, the participants were instructed to write down the corresponding symbol under each digit, as quickly as possible. The number of correctly filled in symbols ( $\max .=133$ ) within the allowed time (120 s) was calculated. A standardized score was then computed from the manual $(M=10, S D=3)$. This subtest has a split-half reliability of 0.86 (Pearson, 2012).

\subsubsection{Paired-associate learning}

Paired-associate learning was assessed with a task during which participants were required to learn associations between pairs of novel/non-existing objects and nonwords. Fifteen novel objects that had been previously rated to 'look nothing like a real object' were selected from Kroll and Potter (1984). The object-likeness ratings were made on a 7-point scale, with a rating of 1 indicating that the non-object "looked very much like a real object," whereas a rating of 7 indicated that the non-object "looked nothing like a real object" (Kroll \& Potter, 1984, p. 60). These novel objects were randomly paired with 15 twosyllable nonwords. The nonwords were adapted from the two-, three-, and four-syllable nonwords used by Rispens and Baker (2012). Ten of those two-syllable nonwords were used. We created the remaining five by adapting the three- and four-syllable items to two-syllable nonwords, keeping the items as dissimilar as possible from real words. Participants were told that they would learn novel names for novel objects, and that these associations should be memorized. The learning included three exposures of each of the pairs. During each exposure phase, the novel object was presented visually on a computer screen while the participant heard the associated nonword via headphones. Each pair was displayed for approximately five seconds. The presentation was randomized. A picture-naming test was used to assess the learning of the pairs. During the picture-naming test, the novel objects were randomly presented one at a time in the center of the screen. Participants were instructed to name the novel object. No feedback was given. There was no time limit to give an answer. The responses were recorded and later phonetically transcribed by a native Dutch speaker using the International Phonetic Alphabet and scored. Accuracy was computed as the proportion of correct phonemes in the correct position within the nonword (for instance, if only one phoneme out of four was produced accurately and in the correct position within the nonword, a score of 0.25 was recorded).

\subsubsection{Cognitive flexibility}

Cognitive flexibility was assessed with the Trail Making test (TMT; Reitan, 1958). The TMT consisted of two parts. In TMT-A, participants were required to sequentially connect 25 numbers distributed on an A3 sheet of paper by drawing lines. In TMT-B, participants were asked to alternate between numbers and letters (1-A-2-B-3 etc.), which required the constant switching between the two dimensions. The score on each part represents the amount of time required to complete the task. The cognitive flexibility measure was calculated as the difference between the time to complete version $B$ minus the time to complete version $A$. This difference score has been shown to provide a relatively pure indicator of executive control abilities (Sánchez-Cubillo et al., 2009). A higher score reflects a longer time taken to complete the 
task. TMT-A has reliability coefficients ranging from 0.69 to 0.94 and TMT-B from 0.66 to 0.86 (Goldstein \& Watson, 1989).

\subsubsection{Non-verbal cognitive ability}

Matrix Reasoning, a subtest of the Dutch adaptation of the WAIS-IVNL (Wechsler, 2012), was used to assess non-verbal cognitive ability. Participants viewed an incomplete matrix of abstract pictures and were asked to select, from five possibilities, the picture that best completed the matrix. Items were presented until participants made four consecutive errors, four errors on five consecutive items, or until the end of the task was reached. The number of correct responses was used to compute a standardized score $(M=10, S D=3)$. This subtest has a split-half reliability of 0.85 (Pearson, 2012).

\subsection{Speechreading and audiovisual processing tasks}

\subsubsection{Speechreading}

Speechreading was assessed with a forced-choice visual-only syllable identification task for Dutch, developed by Jesse and Janse (2012). The stimuli consisted of 10 consonant-vowel (CV) syllables. The consonants were taken from five Dutch viseme classes (bilabial: /p/, /m/; labiodental: /f/, /v/; nonlabial front fricatives: /s/, /z/; other nonlabial front consonants: $/ \mathrm{t} /, / \mathrm{n} /$; other nonlabial back consonants: $/ \mathrm{k} /, / \mathrm{x} /$ ) (van Son, Huiskamp, Bosman, \& Smoorenburg, 1994). The vowel was the same for all syllables $(/ \varnothing /)$. A total of six blocks was presented. Each block consisted of 10 videos of a speaker's face pronouncing the $10 \mathrm{CV}$ syllables, presented in random order. The participants were asked to indicate which consonant the speaker had produced by pressing the corresponding key on a computer keyboard. If a response was not given within five seconds, the next video was presented. No feedback was provided. Overall accuracy (proportion of correct answers) was computed.

\subsubsection{Audiovisual temporal sensitivity}

Audiovisual temporal sensitivity for audiovisual speech and nonspeech events was assessed with a simultaneity judgment task. Speech materials consisted of a McGurk stimulus presented with white noise at $-16 \mathrm{~dB}$ SNR, where participants should perceive /ata/ when hearing a speaker say the syllable /apa/ while seeing the speaker pronouncing / aka/ (McGurk \& MacDonald, 1976). This speech stimulus was created by Groen and Jesse (2013). Non-speech materials consisted of a video showing the clapping hands of a woman, recorded by us. Both sets of stimuli have been used in our previous study (Francisco et al., 2017). In that study, we created SOAs by moving segments in 40 millisecond increments (one frame) from the beginning of the original file to its end (for the audio leads) and from the end of the original file to its beginning (for the audio lags). This process resulted in the creation of 23 speech stimuli with SOAs ranging from $-440 \mathrm{~ms}$ (auditory lead: from $-440 \mathrm{~ms}$ to 0 ) to $+440 \mathrm{~ms}$ (visual lead: from 0 to $+440 \mathrm{~ms}$ ). For both sets of stimuli, participants were asked to indicate as quickly and accurately as possible, by button press, whether the auditory and the visual components of the audiovisual events were in synchrony or not. A total of eight blocks was presented, each consisting of 23 stimuli (22 asynchronous and one synchronous) shown in random order. The proportion of in-synchrony responses (pooled over SOAs) was computed for each participant in each condition. Though it is more common to fit a function to the data of individual participants to estimate measures as the width of the function at half-height, in the present study, it was not possible to provide a good fit to all of our participants' data, and, therefore, we did not add these more common measures as they would not be valid across all participants.

\subsubsection{Audiovisual speech identification}

The stimuli from the speech condition of the simultaneity judgment task were also used to measure audiovisual speech identification at various cross-modal asynchronies. Stimuli, noise, SOAs and number of trials were the same as in the audiovisual temporal sensitivity task, but this time, participants were asked to report what they had perceived (/aka/, /apa/, or /ata) by button press. In the present study, we focused on fusion responses (see also others, e.g. for an analysis of individual differences see Gurler, Doyle, Walker, Magnotti, \& Beauchamp, 2015; for an analyses of SOA on identification see van Wassenhove, Grant, \& Poeppel, 2007). Fusion rates, though not a perfect measure (see Tiippana, 2014), are the most direct measure of audiovisual processing and, therefore, the one used in the present study. For the analysis, the mean fusion rate pooled over the SOAs was entered for each subject.

Both experimental tasks, simultaneity judgment and audiovisual speech identification, followed the same design: (1) a 50 millisecond black screen; (2) a 250 millisecond fixation cross; (3) a 200 millisecond black screen; (4) the stimulus presentation. The two-second videos were played in the center of the screen. The response options were presented after the video offset. At that moment, the participants should report their response by pressing one of the response buttons. If a response was not given within five seconds, the next video was presented. In all tasks, experimental blocks were preceded by an 8-item practice block to familiarize the participants with the procedure. If necessary, further clarifications were given during the practice block. As soon as the experimental blocks began, no more feedback was given.

\subsection{General procedure}

To avoid fatigue, data collection was divided across two sessions. During the first session, participants completed the following tasks: hearing screening, reading, phonological awareness, audiovisual speech identification, matrix reasoning, and non-speech simultaneity judgment. During the second session, they completed the letter naming, digit span, paired-associate learning, speechreading, Simon, digit-symbol substitution, trail making and speech simultaneity judgment tasks. The order of the tests was fixed across subjects.

The computerized cognitive and experimental tasks were presented on a CRT monitor liyama vision master pro451 (19 in. screen), using Presentation software (Version 16.5, www. neurobs.com). During the presentation in the experimental tasks, the refresh rate of the monitor was set to a multiple of the videos' frame rate $(75 \mathrm{~Hz}$, at $1280 \times 1024$ resolution). The audio was presented via Sennheiser headphones (model HD $25 \mathrm{SP}$ ) at a fixed comfortable listening level (60 dB).

\section{Results}

We tested whether audiovisual processing accounts for variance in reading and reading-related abilities, after controlling for the influence of a set of cognitive measures typically associated with reading. To accomplish this, we first conducted a principal component analysis to reduce the number of variables that could account for variance in the reading and reading-related abilities. Additionally, including all measures in this analysis allowed us to understand how they were related with each other. We then submitted these components to hierarchical regression analyses.

Participants' performance in the reading and reading-related, audiovisual and cognitive measures is summarized in Table 1. Although not the focus of this paper, Table 1 also shows group differences statistics. Two-sample independent means $t$-tests were used to test for group differences. When the assumption of the homogeneity of variances was violated, Welch corrections were applied to adjust the degrees of freedom.

We first summarized the cognitive and audiovisual measures by conducting a principal component analysis (PCA) with orthogonal rotation (varimax). As an initial step of the PCA, we examined the correlations between the cognitive and audiovisual measures (Table 2).

Regarding the PCA analysis itself, the Kaiser-Meyer-Olkin measure of sampling adequacy was 0.62 , slightly above the commonly recommended value of at least 0.60 (Tabachnick \& Fidell, 2012), and Bartlett's 
Table 1

Participants' performance in cognitive, reading, and audiovisual measures (mean, standard deviation and minimum and maximum scores)

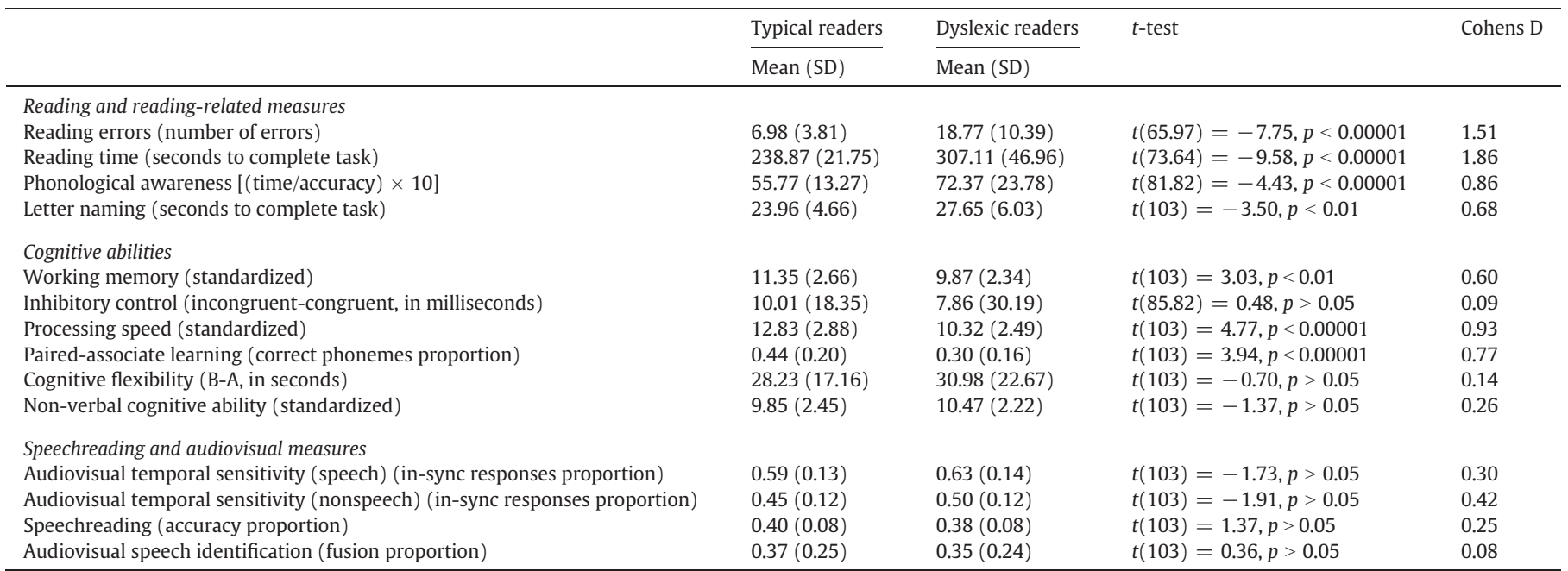

Table 2

Pearson correlations between audiovisual and cognitive measures.

\begin{tabular}{|c|c|c|c|c|c|c|c|c|c|c|}
\hline & & 1 & 2 & 3 & 4 & 5 & 6 & 7 & 8 & 9 \\
\hline 1 & Audiovisual speech identification & & & & & & & & & \\
\hline 2 & Audiovisual temporal sensitivity (speech) & 0.01 & & & & & & & & \\
\hline 3 & Audiovisual temporal sensitivity (nonspeech) & 0.02 & $0.70^{* *}$ & & & & & & & \\
\hline 4 & Speechreading & -0.07 & -0.03 & -0.05 & & & & & & \\
\hline 5 & Paired-associate learning & 0.14 & -0.12 & $-0.19^{*}$ & 0.12 & & & & & \\
\hline 6 & Working memory & 0.18 & $-0.24^{*}$ & $-0.20^{*}$ & 0.10 & $0.45^{* *}$ & & & & \\
\hline 7 & Processing speed & 0.12 & -0.13 & -0.11 & $0.24^{*}$ & $0.29^{* *}$ & $0.41^{* *}$ & & & \\
\hline 8 & Cognitive flexibility & -0.12 & 0.11 & 0.01 & -0.03 & -0.14 & $-0.29^{* *}$ & -0.18 & & \\
\hline 9 & Inhibitory control & 0.12 & 0.04 & 0.06 & -0.05 & -0.10 & -0.10 & -0.04 & 0.01 & \\
\hline 10 & Non-verbal cognitive ability & -0.02 & -0.17 & -0.16 & -0.01 & 0.09 & 0.19 & $0.23^{*}$ & 0.01 & -0.08 \\
\hline
\end{tabular}

${ }^{*} p<0.05,{ }^{* *} p<0.01 ;$ uncorrected for multiple comparisons.

test of sphericity was significant $(\chi 2(36)=147.48, p<0.01)$. Using the criterion of selecting eigenvalues greater than one (Costello \& Osborne, 2005), the PCA extracted three factors. The eigenvalues indicated that these three factors explained $55.21 \%$ of the total variance in the data set $(25.85 \%, 16.34 \%$, and $13.02 \%$, respectively). The rotated factor loadings for each of the nine variables are presented in Table 3. To determine factor consistency, a loading of \pm 0.50 was used as a criterion (Costello \& Osborne, 2005). Non-verbal cognitive ability was excluded from the analysis because it did not contribute to a simple factor structure and failed to meet the minimum criterion. The PCA demonstrated that the remaining predictors could be consolidated into three different factors.

Table 3

Component structure identified in principal components analysis with orthogonal rotation (loadings $>00.50$ are presented in bold).

\begin{tabular}{|c|c|c|c|}
\hline & $\begin{array}{l}\text { Cognitive } \\
\text { abilities }\end{array}$ & $\begin{array}{l}\text { Audiovisual temporal } \\
\text { sensitivity }\end{array}$ & $\begin{array}{l}\text { Visual speech } \\
\text { processing }\end{array}$ \\
\hline Working memory & 0.771 & -0.196 & -0.050 \\
\hline Processing speed & 0.682 & -0.022 & -0.225 \\
\hline Paired-associate learning & 0.656 & -0.132 & -0.132 \\
\hline Cognitive flexibility & -0.517 & -0.011 & -0.194 \\
\hline $\begin{array}{l}\text { Audiovisual temporal } \\
\text { sensitivity (nonspeech) }\end{array}$ & -0.090 & 0.913 & 0.059 \\
\hline $\begin{array}{l}\text { Audiovisual temporal } \\
\text { sensitivity (speech) }\end{array}$ & -0.126 & 0.907 & -0.010 \\
\hline Speechreading & 0.266 & 0.075 & -0.605 \\
\hline $\begin{array}{l}\text { Audiovisual speech } \\
\text { identification }\end{array}$ & 0.432 & 0.086 & 0.609 \\
\hline Inhibitory control & -0.055 & 0.056 & 0.592 \\
\hline
\end{tabular}

The first factor, named cognitive abilities, included working memory, processing speed, paired-associate learning, and cognitive flexibility. The second factor, named audiovisual temporal sensitivity, included speech and non-speech audiovisual temporal sensitivity. Finally, speechreading, audiovisual speech identification and inhibitory control were included in the third factor. Though this third factor also included other abilities, it was named visual speech processing since, as we will show below, speechreading was the measure driving the results found for the factor. Composite scores were created for each of the three factors, based on the mean of the items that had their primary loadings on that factor.

We next focused on the relationships between reading and readingrelated abilities and the three factors from the PCA: cognitive abilities, audiovisual temporal sensitivity, and visual speech processing. Correlational tests were run in order to provide an initial descriptive overview of these relationships. As can be seen in Table 4, the reading abilities correlated with each other, as expected. Cognitive abilities correlated significantly with all the reading abilities and audiovisual temporal sensitivity correlated with the number of reading errors made (correlations uncorrected for multiple comparisons).

Four multiple regression analyses were carried out in order to determine the variables that accounted for variance in reading errors, reading time, phonological awareness, and letter naming. Hierarchical regression analyses were used to test whether audiovisual temporal sensitivity and visual speech processing could account for variance in the performance on the reading and reading-related skills tasks, after controlling for cognitive abilities.

All the assumptions required to perform a regression analysis were met. The dependent variables were log-transformed to create normally 
Table 4

Pearson correlations between dependent variables (reading and reading-related) and predictors (cognitive abilities, audiovisual sensitivity and visual speech processing).

\begin{tabular}{|c|c|c|c|c|c|c|c|}
\hline & & 1 & 2 & 3 & 4 & 5 & 6 \\
\hline 1 & Reading errors & & & & & & \\
\hline 2 & Reading time & $0.674^{* *}$ & & & & & \\
\hline 3 & Phonological awareness & $0.338^{* *}$ & $0.504^{* *}$ & & & & \\
\hline 4 & Letter naming & $0.247^{*}$ & $0.423^{* *}$ & 0.135 & & & \\
\hline 5 & Cognitive abilities & $-0.494^{* *}$ & $-0.521^{* *}$ & $-0.411^{* *}$ & $-0.300^{* *}$ & & \\
\hline 6 & Audiovisual temporal sensitivity & $0.209^{*}$ & 0.026 & 0.049 & 0.055 & 0.000 & \\
\hline 7 & Visual speech processing & 0.009 & -0.013 & -0.115 & -0.003 & 0.000 & 0.000 \\
\hline
\end{tabular}

${ }^{*} p<0.05,{ }^{* *} p<0.01$; uncorrected for multiple comparisons.

distributed measures. Visual inspection of the histograms and skewness (reading errors: skewness $=-0.522, S E=0.239$; reading time: skewness $=0.574, S E=0.239$; phonological awareness: skewness $=0.502$, $S E=0.239$; letter naming: skewness $=-0.455, S E=0.239$ ) and kurtosis (reading errors: kurtosis $=0.699, S E=0.474$; reading time: kurtosis $=0.186, S E=0.474$; phonological awareness: kurtosis $=0.271$, $S E=0.474$; letter naming: kurtosis $=-0.120, S E=0.474$ ) measures indicated that the departure from normality was not too extreme in any of the transformed variables. All independent measures were factors and were also normally distributed: Visual inspection of the histograms and skewness (cognitive abilities: skewness $=-0.106, S E=$ 0.239; audiovisual temporal sensitivity: skewness $=0.317, S E=$ 0.239; visual speech processing: skewness $=-0.315, S E=0.239$ ) and kurtosis (cognitive abilities: kurtosis $=0.142, S E=0.474$; audiovisual temporal sensitivity: kurtosis $=-0.427, S E=0.474$; visual speech processing: kurtosis $=0.125, S E=0.474$ ) measures indicated that the departure from normality was not too extreme in any of the factors. Normal distributions were also found within reading group, for all variables. Next, an analysis of standard residuals was carried out on the data to identify outliers. While no outliers were identified in reading errors (Std. Residual Min $=-3.20$, Std. Residual Max $=2.11$ ) or in reading time (Std. Residual Min $=-2.22$, Std. Residual Max $=3.25$ ), there was one outlier in the phonological awareness measure (Std. Residual Min $=-2.06$, Std. Residual Max = 3.36) and one outlier in the letter naming measure (Std. Residual Min $=-2.58$, Std. Residual Max = 3.38). Because the exclusion of the two outliers did not change any of the results found, those participants were kept in the sample. Additionally, tests of the assumption of collinearity indicated that multicollinearity was not problematic (all models: Tolerance $>0.10$, $\mathrm{VIF}<4$ ). The only exceptions were the interaction terms. It has been argued, however, that multicollinearity caused by the inclusion of powers or products of other variables is less of a concern (Allison, 2012). To further investigate whether multicollinearity could be problematic in the present study, we computed correlations between the three factors (cognitive abilities, audiovisual temporal sensitivity, and visual speech processing) and the interactions between each of those factors and group. Each factor correlated significantly only with the interaction term that included that factor. Hence, we assumed that the multicollinearity found for these data is not of concern. Also, all histograms of standardized residuals indicated that the data contained approximately normally distributed errors, as did the normal P-P plot of standardized residuals, which showed points that were not completely on the line, but close. The scatterplots of standardized residuals showed that the data met the assumptions of homogeneity of variance and linearity. Lastly, Durbin-Watson tests indicated, in all analyses, $d$ values between the two critical values of $1<d<3$ and, therefore, we could assume that there was no first order linear auto-correlation in the data.

Three identical models were developed for each of the dependent variables. In each case, the first model comprised the cognitive abilities factor, the second model also had cognitive abilities but also included audiovisual temporal sensitivity and visual speech processing, and the third model consisted of the second model and, in addition, the interactions between each of the factors of model 2 and reading group (typical versus dyslexic readers). These interactions were included to make sure that the results found were not the consequence of the inclusion of two different groups of readers. Tables 5 to 8 summarize the outcomes of these analyses.

Cognitive abilities and audiovisual temporal sensitivity, but not visual speech processing, made unique contributions in accounting for variance in the number of reading errors made. Audiovisual temporal sensitivity became only marginally significant in the third model (when the interactions were included). Though significant, the third model is characterized by a decrease in the $R$-squared and a non-significant F-change. Therefore, Model 2, showing both cognitive abilities and audiovisual temporal sensitivity as significant measures in explaining the variance in the number of reading errors made, is a better model than Model 3. When analyzed separately, both speech $(r=0.25$, $p<0.01)$ and non-speech $(r=0.30, p<0.01)$ audiovisual temporal sensitivity correlated positively with the number of reading errors made.

In contrast, only the factor reflecting cognitive abilities accounted for variance in reading time, as can be seen in Table 6.

Variance in phonological awareness (Table 7) was significantly accounted for by cognitive abilities in the first and the second model. However, this result did not hold when the interactions were added (third model). Instead, the interaction between visual speech processing and reading group became significant.

Table 5

Summary of hierarchical regression analysis for variables accounting for variance in reading errors.

\begin{tabular}{|c|c|c|c|c|c|c|c|c|c|}
\hline \multirow[b]{2}{*}{ Variables } & \multicolumn{3}{|l|}{ Model 1} & \multicolumn{3}{|l|}{ Model 2} & \multicolumn{3}{|c|}{ Model 3} \\
\hline & $B$ & $S E$ & $\beta$ & $B$ & $S E$ & $B$ & $B$ & $S E$ & $\beta$ \\
\hline Cognitive abilities & -0.38 & 0.06 & $-0.49^{* *}$ & -0.38 & 0.06 & $-0.49^{* *}$ & -0.50 & 0.23 & $-0.65^{* *}$ \\
\hline Audiovisual temporal sensitivity & & & & 0.16 & 0.06 & $0.21^{*}$ & 0.34 & 0.21 & $0.45^{\wedge}$ \\
\hline Visual speech processing & & & & 0.02 & 0.06 & 0.03 & 0.04 & 0.21 & 0.06 \\
\hline Group $\times$ cognitive abilities & & & & & & & 0.08 & 0.14 & 0.17 \\
\hline Group $\times$ audiovisual temporal sensitivity & & & & & & & -0.12 & 0.13 & -0.26 \\
\hline Group $\times$ visual speech processing & & & & & & & -0.01 & 0.13 & -0.02 \\
\hline Adjusted $R^{2}$ & 0.24 & & & 0.27 & & & 0.25 & & \\
\hline$F$ for change in $R^{2}$ & $32.85^{* *}$ & & & $3.08^{*}$ & & & 0.39 & & \\
\hline
\end{tabular}

$\wedge p<0.1$.

$* p<0.05$

** $p<0.01$. 
Table 6

Summary of hierarchical regression analysis for variables accounting for variance in reading time.

\begin{tabular}{|c|c|c|c|c|c|c|c|c|c|}
\hline \multirow[b]{2}{*}{ Variables } & \multicolumn{3}{|l|}{ Model 1} & \multicolumn{3}{|c|}{ Model 2} & \multicolumn{3}{|c|}{ Model 3} \\
\hline & $B$ & $S E$ & $\beta$ & $B$ & SE & $\beta$ & $B$ & $S E$ & $\beta$ \\
\hline Cognitive abilities & -0.09 & 0.02 & $-0.52^{* *}$ & -0.09 & 0.02 & $-0.52^{* *}$ & -0.10 & 0.05 & $-0.59^{\wedge}$ \\
\hline Audiovisual temporal sensitivity & & & & 0.01 & 0.02 & 0.03 & 0.02 & 0.05 & 0.09 \\
\hline Visual speech processing & & & & -0.01 & 0.02 & -0.01 & 0.01 & 0.05 & 0.08 \\
\hline Group $\times$ cognitive abilities & & & & & & & 0.01 & 0.03 & 0.08 \\
\hline Group $\times$ audiovisual temporal sensitivity & & & & & & & -0.01 & 0.03 & -0.06 \\
\hline Group $\times$ visual speech processing & & & & & & & -0.01 & 0.03 & -0.08 \\
\hline Adjusted $R^{2}$ & 0.26 & & & 0.25 & & & 0.23 & & \\
\hline$F$ for change in $R^{2}$ & $38.30^{* *}$ & & & 0.08 & & & 0.06 & & \\
\hline
\end{tabular}

$\wedge p<0.1$.

$* p<0.05$.

** $p<0.01$.

Table 7

Summary of hierarchical regression analysis for variables accounting for variance in phonological awareness.

\begin{tabular}{|c|c|c|c|c|c|c|c|c|c|}
\hline \multirow[b]{2}{*}{ Variables } & \multicolumn{3}{|l|}{ Model 1} & \multicolumn{3}{|c|}{ Model 2} & \multicolumn{3}{|l|}{ Model 3} \\
\hline & $B$ & SE & $\beta$ & $B$ & $S E$ & $\beta$ & $B$ & $S E$ & $\beta$ \\
\hline Cognitive abilities & -0.12 & 0.03 & $-0.41^{* *}$ & -0.12 & 0.03 & $-0.41^{* *}$ & -0.11 & 0.10 & -0.36 \\
\hline Audiovisual temporal sensitivity & & & & 0.02 & 0.03 & 0.06 & 0.01 & 0.09 & 0.02 \\
\hline Visual speech processing & & & & -0.02 & 0.03 & -0.08 & 0.14 & 0.08 & 0.46 \\
\hline Group $\times$ cognitive abilities & & & & & & & -0.01 & 0.06 & -0.04 \\
\hline Group $\times$ audiovisual temporal sensitivity & & & & & & & 0.01 & 0.05 & 0.07 \\
\hline Group $\times$ visual speech processing & & & & & & & -0.11 & 0.05 & $-0.58^{*}$ \\
\hline Adjusted $R^{2}$ & 0.16 & & & 0.16 & & & 0.16 & & \\
\hline$F$ for change in $R^{2}$ & $20.94^{* *}$ & & & 0.62 & & & 1.38 & & \\
\hline
\end{tabular}

* $p<0.05$.

** $p<0.01$.

In an attempt to clarify this interaction and to understand which of the variables included in the visual speech processing factor were driving this interaction, we further looked into the relationships between a) speechreading and phonological awareness, b) audiovisual speech identification and phonological awareness and c) inhibitory control and phonological awareness. As can be seen in Fig. 1, speechreading (panel A) but not audiovisual speech identification (panel B) or inhibitory control (panel C) drove the interaction between visual speech processing and phonological awareness. The dyslexic readers who scored better on speechreading scored lower on phonological awareness. This was not the case for the typical readers.

To further confirm this result, we tested for differences in phonological awareness between the dyslexic readers who scored high in speechreading and the ones who scored low in speechreading. The same was done for the typical readers. To do that, we first computed a median split of the speechreading measure. Two-sample independent means $t$-tests were then carried out per group. This analysis confirmed that dyslexic readers who scored higher in speechreading differed from those who scored lower in speechreading. The best dyslexic speechreaders had lower phonological awareness scores than the worst dyslexic speechreaders $(t(51)=-2.57, p<0.05)$. The typical speechreaders' groups did not differ significantly.

Lastly, only the cognitive abilities factor accounted for variance in letter naming (Table 8). Nevertheless, that factor was no longer significant when the interactions were added.

\section{Discussion}

Our main aim was to test whether individual differences in audiovisual processing account for variance in reading and reading-related abilities. In summary, audiovisual temporal sensitivity (both speech and non-speech) accounted for variance in the number of reading errors, even after controlling for the effect of cognitive abilities typically associated with reading. Reading group (typical vs. dyslexic) did not

Table 8

Summary of hierarchical regression analysis for variables accounting for variance in letter naming.

\begin{tabular}{|c|c|c|c|c|c|c|c|c|c|}
\hline \multirow[b]{2}{*}{ Variables } & \multicolumn{3}{|l|}{ Model 1} & \multicolumn{3}{|c|}{ Model 2} & \multicolumn{3}{|c|}{ Model 3} \\
\hline & B & SE & $\beta$ & $B$ & $S E$ & $\beta$ & $B$ & $S E$ & $\beta$ \\
\hline Cognitive abilities & -0.06 & 0.02 & $-0.30^{* *}$ & -0.06 & 0.02 & $-0.30^{* *}$ & -0.06 & 0.07 & -0.26 \\
\hline Audiovisual temporal sensitivity & & & & 0.01 & 0.02 & 0.04 & -0.10 & 0.07 & -0.45 \\
\hline Visual speech processing & & & & -0.01 & 0.02 & -0.3 & -0.11 & 0.07 & -0.48 \\
\hline Group $\times$ cognitive abilities & & & & & & & -0.01 & 0.04 & -0.06 \\
\hline Group $\times$ audiovisual temporal sensitivity & & & & & & & 0.07 & 0.04 & 0.49 \\
\hline Group $\times$ visual speech processing & & & & & & & -0.06 & 0.04 & 0.45 \\
\hline Adjusted $R^{2}$ & 0.09 & & & 0.06 & & & 0.08 & & \\
\hline$F$ for change in $R^{2}$ & $10.15^{* *}$ & & & 0.14 & & & 1.56 & & \\
\hline
\end{tabular}

$* p<0.05$.

** $p<0.01$. 

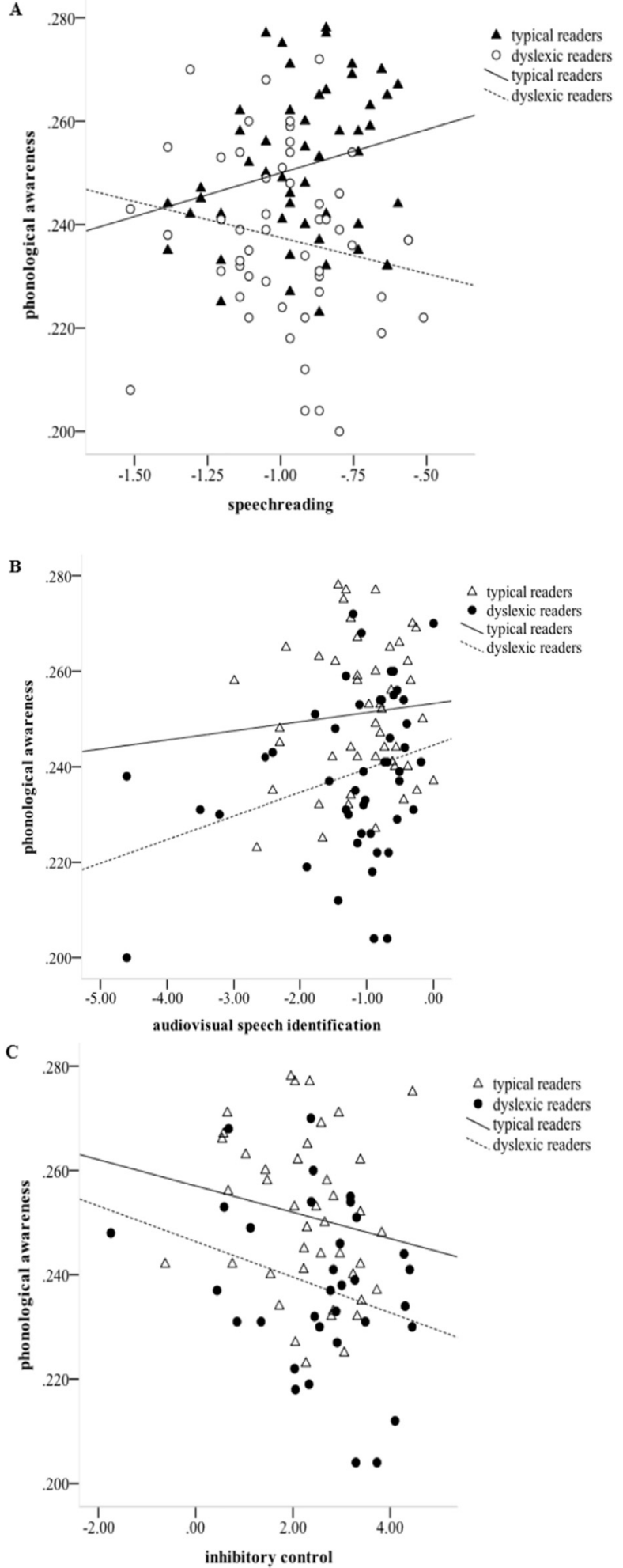

Fig. 1. Relationship between phonological awareness and speechreading (panel A), audiovisual speech identification (panel B), and inhibitory control per group (panel C) on a log scale. Lines represent linear regression fits, computed using the least squares method. To facilitate the reading of this figure, better scores represent better performance for all measures.

moderate this effect, suggesting that these effects are independent of diagnostic status. Additionally, the interaction between phonetic identification in visual speech and group was a unique contributor to variance in phonological awareness. Specifically, dyslexic readers who scored higher on speechreading, scored lower on phonological awareness.
Speechreading did not relate to phonological awareness in the typical readers.

Variance in the number of reading errors made was accounted for by both cognitive abilities and audiovisual temporal sensitivity in both participant groups. Participants who had lower scores in the cognitive abilities factor made more reading errors. Associations between paired-associate learning (e.g., Hulme et al., 2007), working memory (e.g., Christopher et al., 2012), processing speed (e.g., Park \& Lombardino, 2013), cognitive flexibility (Krause \& Moore, 1997), and reading ability are well established in the literature. In our study, audiovisual temporal sensitivity made a further contribution to explaining the variance in the number of reading errors. Participants who gave more in-synchrony answers made more reading errors. And that was true for both the speech and the non-speech events (i.e., there was no evidence that audiovisual temporal sensitivity for speech and nonspeech stimuli had distinct effects on reading errors). This finding is consistent with the results we have previously reported (Francisco et al., 2017; and see Chen, Zhang, Ai, Xie, \& Meng, 2016 for similar results in Chinese children) and extends them by showing that dyslexic readers are not only less sensitive to the temporal synchrony of audiovisual events than typical readers, but that the degree of sensitivity explains variance in reading ability in both typical and dyslexic readers, even after controlling for measures that relate to reading. As previously argued, a general audiovisual deficit reflected in wider temporal windows of audiovisual processing (i.e., more in-synchrony responses, as shown in the present study) could result in impaired reading. Given that adequate associations between graphemes and phonemes occur in narrow time windows (Froyen et al., 2008), an audiovisual deficit that results in the widening of audiovisual temporal windows could impair the development of such associations and, consequently, reading. That is, it could hamper the formation of adequate representations, creating ambiguity in the correspondences between graphemes and phonemes (Wallace \& Stevenson, 2014). This could result in reductions in the speed with which printed representations are decoded and lead to more errors in the accurate pairing of orthography and speech sounds (Hairston et al., 2005). These arguments should, nevertheless, be taken cautiously, since the results of our regression analyses do not allow for conclusions about causation. Because of this, we cannot exclude the possibility that the relationship might be reversed, such that improvements in reading might lead to a narrowing of the audiovisual temporal window or that a third variable created both effects: improvements in reading and narrowing of the audiovisual temporal window.

The relationship between reading and audiovisual processing has also been addressed in intervention studies using audiovisual training to improve reading. For instance, Žarić et al. (2015) showed in an ERP study that, through reading instruction and training in letter-speech sound associations, the ability to integrate letters and speech sounds could be improved in dyslexic children. In other intervention studies focusing on letter-speech sound mapping training, dyslexic children showed: a) significant improvement (and at a faster rate than typical readers) in post-tests assessing word reading and spelling measures (González et al., 2015); b) a reduction in the ERP component elicited by words and symbols (N170) (González et al., 2016). Longitudinal studies, focusing on the development of the association between reading and audiovisual processing might shed additional light on the relationship between reading and audiovisual processing.

Yet another possibility is that deficits in certain cognitive abilities could impact audiovisual processing and explain the differences in audiovisual processing in individuals with different reading ability levels. The analysis of group differences was not the focus of this paper (see Francisco et al., 2017 for such an analysis) and, therefore, no strict criteria were applied in the definition of the typical and dyslexic readers groups. Nevertheless, typical and dyslexic readers differed significantly in working memory and in processing speed. Working memory and processing have been shown to be important components of speechreading (Feld \& Sommers, 2009; Lyxell \& Rönnberg, 1989, 
1993). Thus, a deficit in working memory and/or in processing speed could explain an audiovisual deficit and simultaneously contribute to or aggravate a reading deficit (Beneventi, Tønnessen, Ersland, \& Hugdahl, 2010; Stoodley \& Stein, 2006).

In the present study we also showed that variance in reading time was accounted for only by cognitive abilities. Participants who had lower scores in the cognitive abilities factor were slower readers. This is consistent with the results found for the number of reading errors: The associations between reading and the measures included in the cognitive abilities factor (paired-associate learning, working memory, processing speed, cognitive flexibility, inhibitory control) are amply supported by the literature (Hulme et al., 2007; Christopher et al., 2012; Park \& Lombardino, 2013; Krause \& Moore, 1997; Chiappe et al., 2000).

Audiovisual temporal sensitivity was a unique predictor of variance in reading errors, but not of variance in reading time. This result does not seem to be due to the instructions given (participants were told that accuracy was more important than speed), since an effect of the cognitive abilities factor was still present in reading time. Alternatively, accuracy and speed may be influenced by distinct underlying processes. In a study comparing subgroups of dyslexic adults in phonological and orthographic processing, Leinonen et al. (2001) showed that inaccurate phonological decoding appeared to determine the number of errors made during reading, while inability to effectively and rapidly access words manifested as slow reading speed. Audiovisual temporal sensitivity might be associated with phonological decoding more than with lexical access speed. This assumption could explain why audiovisual temporal sensitivity accounted for variance in reading errors but not in reading time.

Another main result of the present study was that variance in phonological awareness was accounted for by the interaction between visual speech processing and reading group. Though inhibitory control and fusion rates were also included in the visual-speech-processing factor, only speechreading drove the association between phonological awareness and visual speech processing. We found that dyslexic readers with higher scores in speechreading were worse at phonological awareness than those with lower scores in speechreading, that is, dyslexic readers with a greater impairment in phonological processing were better speechreaders. No differences were found between the typical readers scoring high and low on speechreading.

This evidence is in line with results reported in a functional imaging study, where typical and dyslexic adult readers were presented with phonetically matching and conflicting audiovisual vowels (Pekkola et al., 2006). When presented with audiovisual speech, dyslexic readers displayed enhanced brain activity in areas dedicated to visual and motor-articulatory processes when compared to typical readers. According to Pekkola et al. (2006), dyslexic readers may have learned to compensate for their deficits by relying more on speechreading input, that is, dyslexic readers might place more reliance on visual speech because processing auditory speech is problematic. More recently, also MacSweeney, Brammer, Waters, and Goswami (2009) showed greater inferior frontal gyrus activation in dyslexic readers and deaf individuals in contrast to controls in a rhyme judgment task with pictures. Given the involvement of the inferior frontal gyrus in articulation, this suggests, again, greater reliance on visual speech during phonological processing when auditory processes are absent (deaf group) or impaired (dyslexic group). As some individuals with dyslexia have impaired hearing (Bernstein, Tucker, \& Demorest, 2000), those readers might rely more on the information taken from visual speech.

The argument that dyslexic readers might rely more on speechreading input, however, seems to be at odds with studies showing positive correlations between phonological processing and speechreading in adult dyslexic readers (Mohammed, Campbell, MacSweeney, Barry, \& Coleman, 2006). While in the present study typical and dyslexic readers differed significantly in the reading measures applied, in Mohammed et al.'s study, dyslexic readers' reading skills did not differ significantly from those of the typical readers. In the present study, only the dyslexic readers with the lowest scores in phonological awareness had better speechreading scores. We might have captured a dyslexic sub-group more impaired in phonological awareness than any of the participants in the Mohammed et al. study. Differences in reading ability between our sample and the one tested in Mohammed et al. may then explain the differences in the results reported.

An enhanced reliance on speechreading in dyslexia is also not consistent with studies reporting impaired speechreading in dyslexic readers (de Gelder \& Vroomen, 1998; Ramirez \& Mann, 2005). De Gelder and Vroomen (1998) tested dyslexic children rather than adults. The evidence that children are less proficient in speechreading when compared to adults (e.g. McGurk \& MacDonald, 1976) might explain the differences between ours and de Gelder and Vroomen's results. Considering that speechreading ability develops with age (van Linden \& Vroomen, 2008), adult readers are expected to make more efficient use of speechreading than children. In Ramirez and Mann's study, dyslexic adult readers were also poorer at identifying visual cues. The sample assessed in Ramirez and Mann's study was noticeably small ( $\mathrm{N}=$ 10 ), which limits the generalization of their results. It is also worth noting that the dyslexic readers tested in the present study were all highly educated adults, whereas in the Ramirez and Mann study some dyslexic readers had lower education levels (some of them having only completed high-school education). Higher and lower educated dyslexic readers might develop different strategies to deal with their reading difficulties. Contrary to de Gelder and Vroomen's and Ramirez and Mann's results, and in line with the results reported in the present study, Baart, de Boer-Schellekens, and Vroomen (2012) showed that dyslexic and typical adult readers perform about the same in speechreading and are equally able to use information from visual speech to recalibrate their auditory phonetic categories.

In the present study we also showed that letter naming was accounted for only by cognitive abilities. In this study, letter naming was quantified as the time taken to name a set of letters in a discrete task. Although the use of a discrete task may reduce the influence of memory processes during naming (de Pessemier \& Andries, 2009), it has been suggested that serial letter naming is more strongly related to reading than discrete letter naming (Georgiou, Parrila, Cui, \& Papadopoulos, 2013 and see Kirby, Georgiou, Martinussen, \& Parrila, 2010 for a review). Thus, the use of a discrete task complicates further conclusions about both the meaning of the present results and the nature of the letter naming ability, that is, whether it is a general phonological processing construct (Torgesen et al., 1994; Wagner \& Torgesen, 1987) or whether it reflects cognitive processes other than the ones related to phonological processing (Bowers \& Wolf, 1993; Kirby et al., 2003; Manis, Doi, \& Bhadha, 2000; Park \& Lombardino, 2013; Wolf et al., 2000). That the cognitive abilities factor accounted for variance in the letter naming seems to point towards the latter possibility.

Regarding our secondary aim to contribute to the debate on the nature of dyslexia, our results are consistent with a hybrid perspective of dyslexia, such as that proposed by Pennington et al. (2012). According to Pennington et al. (2012), the associations between predictors and reading ability are not deterministic, but probabilistic. Consequently, there are multiple possible pathways to reading impairment, which may translate into multiple profiles of dyslexia. And, indeed, in the present study, a subset of dyslexic readers who showed lower scores in phonological awareness scored higher on the speechreading measure. This suggests that speechreading might be relevant for some dyslexic readers. Increasing the sample heterogeneity may shed additional light on this matter. In the present study, we may have tested a sample that represents a middle section in the reading ability continuum - despite consisting of typical readers with generally above average reading performance and of dyslexic readers with generally below average reading performance, we had a highly educated sample. The 
inclusion of groups of individuals from outside the university context may aid to the understanding of the associations between reading and audiovisual processing.

\section{Conclusion}

The aim of the present study was to clarify whether audiovisual processing accounted for variance in reading and reading-related abilities beyond the effect of other cognitive abilities, and how, if present, that association could contribute to the understanding of the nature of dyslexia. We showed that audiovisual temporal sensitivity contributed uniquely to variance in reading errors, even after controlling for the influence of cognitive abilities typically associated with reading. This finding substantiates the role of audiovisual processing in reading and is consistent with studies showing an audiovisual deficit in dyslexic readers. Additionally, we showed that visual speech processing accounted for variance in phonological awareness in dyslexic but not in typical readers. This suggests that some dyslexic readers may have learned to compensate for their deficits in auditory speech perception by relying more on visual speech. Our results further indicate that audiovisual processing and speechreading contribute independently to different processes: While audiovisual temporal sensitivity accounted for variance in reading errors, speechreading accounted for variance in phonological awareness. Furthermore, our results are consistent with a hybrid perspective of dyslexia, such as the one proposed by Pennington et al. (2012). It appears that there are multiple possible pathways to reading impairment, and hence multiple profiles of dyslexia.

\section{Acknowledgements}

The second author (MAG) was supported by an Innovational Research Incentives Scheme Veni grant (\#275-89-017) from the Netherlands Organisation for Scientific Research. The funding source had influence neither on the conduction of the research, nor on preparation of the article. The second author (MAG) and the third author (AJ) contributed equally to the paper. The authors wish to thank all participants for their cooperation and Douwe Horsthuis for the assessment of the participants' performance in reading and paired-associate learning measures.

\section{References}

Allison, P. (2012). When can you safely ignore multicollinearity? [Blog post]. Retrieved from http://statisticalhorizons.com/multicollinearity (September 10)

Baart, M., de Boer-Schellekens, L., \& Vroomen, J. (2012). Lipread-induced phonetic recalibration in dyslexia. Acta Psychologica, 140, 91-95.

Bast, J., \& Reitsma, P. (1998). Analyzing the development of individual differences in terms of Matthew effects in reading: Results from a Dutch longitudinal study. Developmental Psychology, 34(6), 1373.

Bekebrede, J., van der Leij, A., Plakas, A., Share, D., \& Morfidi, E. (2010). Dutch dyslexia in adulthood: Core features and variety. Scientific Studies of Reading, 14(2), 183-210.

Beneventi, H., Tønnessen, F. E., Ersland, L., \& Hugdahl, K. (2010). Working memory deficit in dyslexia: Behavioral and FMRI evidence. International Journal of Neuroscience, 120(1), 51-59.

Bernstein, L. E., Tucker, P. E., \& Demorest, M. E. (2000). Speech perception without hearing. Perception \& Psychophysics, 62(2), 233-252.

Bishop, D. V., \& Snowling, M. J. (2004). Developmental dyslexia and specific language impairment: Same or different? Psychological Bulletin, 130(6), 858-886.

Blau, V., van Atteveldt, N., Ekkebus, M., Goebel, R., \& Blomert, L. (2009). Reduced neural integration of letters and speech sounds links phonological and reading deficits in adult dyslexia. Current Biology, 19(6), 503-508.

Blau, V., Reithler, J., van Atteveldt, N., Seitz, J., Gerretsen, P., Goebel, R., \& Blomert, L. (2010). Deviant processing of letters and speech sounds as proximate cause of reading failure: A functional magnetic resonance imaging study of dyslexic children. Brain, 133(3), 868-879.

Borgmann, K. W., Risko, E. F., Stolz, J. A., \& Besner, D. (2007). Simon says: Reliability and the role of working memory and attentional control in the Simon task. Psychonomic Bulletin E Review, 14(2), 313-319.

Bowers, P. G., \& Wolf, M. (1993). Theoretical links among naming speed, precise timing mechanisms and orthographic skill in dyslexia. Reading and Writing, 5(1), 69-85.
Breznitz, Z., \& Meyler, A. (2003). Speed of lower-level auditory and visual processing as a basic factor in dyslexia: Electrophysiological evidence. Brain and Language, 85(2), $166-184$.

Caravolas, M. (2004). Spelling development in alphabetic writing systems: A cross-linguistic perspective. European Psychologist, 9(1), 3-14

Chen, L., Zhang, M., Ai, F., Xie, W., \& Meng, X. (2016). Crossmodal synesthetic congruency improves visual timing in dyslexic children. Research in Developmental Disabilities, 55 , $14-26$.

Chiappe, P., Siegel, L. S., \& Hasher, L. (2000). Working memory, inhibitory control, and reading disability. Memory \& Cognition, 28(1), 8-17.

Chiappe, P., Stringer, R., Siegel, L. S., \& Stanovich, K. E. (2002). Why the timing deficit hypothesis does not explain reading disability in adults. Reading and Writing, 15(1-2), 73-107.

Christopher, M. E., Miyake, A., Keenan, J. M., Pennington, B., DeFries, J. C., Wadsworth, S. J., ... Olson, R. K. (2012). Predicting word reading and comprehension with executive function and speed measures across development: A latent variable analysis. Journal of Experimental Psychology: General, 141(3), 470.

Conrey, B., \& Pisoni, D. B. (2006). Auditory-visual speech perception and synchrony detection for speech and nonspeech signals. The Journal of the Acoustical Society of America, 119(6), 4065-4073.

Costello, A. B., \& Osborne, J. W. (2005). Best practices in exploratory factor analysis: Four recommendations for getting the most from your analysis. Practical Assessment, Research \& Evaluation, 10, 1-9.

de Gelder, B., \& Vroomen, J. (1998). Impaired speech perception in poor readers: Evidence from hearing and speech reading. Brain and Language, 64, 269-281.

de Jong, P. F., \& van der Leij, A. (1999). Specific contributions of phonological abilities to early reading acquisition: Results from a Dutch latent variable longitudinal study Journal of Educational Psychology, 91(3), 450.

de Jong. P. F., \& van der Leij, A. (2002). Effects of phonological abilities and linguistic comprehension on the development of reading. Scientific Studies of Reading, 6(1), 51-77.

de Pessemier, P., \& Andries, C. (2009). Test voor Gevorderd Lezen en Schrijven. Antwerpen, Belgium-Apeldoorm. The Netherlands: Garant

Elbro, C., Nielsen, I., \& Petersen, D. K. (1994). Dyslexia in adults: Evidence for deficits in non-word reading and in the phonological representation of lexical items. Annals of Dyslexia, 44(1), 203-226.

Feld, J. E., \& Sommers, M. S. (2009). Lipreading, processing speed, and working memory in younger and older adults. Journal of Speech, Language, and Hearing Research, 52(6), 1555-1565.

Flesch, R. (1948). A new readability yardstick. Journal of Applied Psychology, 32(3), 221.

Francisco, A. A., Jesse, A., Groen, M. A., \& McQueen, J. M. (2017). A general audiovisual temporal processing deficit in adult readers with dyslexia. Journal of Speech, Language, and Hearing Research, 60, 144-158.

Froyen, D., Van Atteveldt, N., Bonte, M., \& Blomert, L. (2008). Audiovisual enhancement of the MMN to speech-sounds indicates early and automatic integration of letters and speech-sounds. Neuroscience Letters, 430(1), 23-28.

Froyen, D., Willems, G., \& Blomert, L. (2011). Evidence for a specific cross-modal association deficit in dyslexia: An electrophysiological study of letter-speech sound processing. Developmental Science, 14(4), 635-648.

Gaskins, I. W. (2008). Developing cognitive flexibility in word reading among beginning and struggling readers. In K. B. Cartwright (Ed.), Literacy processes: Cognitive flexibility in learning and teaching (pp. 90-113). New York, NY US: Guilford Press.

Georgiou, G. K., Parrila, R., Kirby, J. R., \& Stephenson, K. (2008). Letter naming components and their relationship with phonological awareness, orthographic knowledge, speed of processing, and different reading outcomes. Scientific Studies of Reading, 12(4), 325-350.

Georgiou, G. K., Parrila, R., Cui, Y., \& Papadopoulos, T. C. (2013). Why is rapid automatized naming related to reading? Journal of Experimental Child Psychology, 115(1), 218-225.

Goldstein, G., \& Watson, J. R. (1989). Test-retest reliability of the Halstead-Reitan battery and the WAIS in a neuropsychiatric population. Clinical Neuropsychologist, 3 $265-273$.

González, G. F. Žarić, G. Tijms, J., Bonte, M., Blomert, L., \& van der Molen, M. W. (2015). A randomized controlled trial on the beneficial effects of training letter-speech sound integration on reading fluency in children with dyslexia. PloS One, 10(12).

González, G. F., Žarić, G., Tijms, J., Bonte, M., Blomert, L., Leppänen, P., \& van der Molen, M. W. (2016). Responsivity to dyslexia training indexed by the N170 amplitude of the brain potential elicited by word reading. Brain and Cognition, 106, 42-54.

Groen, M. A., \& Jesse, A. (2013). Audiovisual speech perception in children and adolescents with developmental dyslexia: No deficit with McGurk stimuli. In S. Ouni, F. Berthommier, \& A. Jesse (Eds.), Proceedings of the international conference on audio-visual speech processing (pp. 77-80).

Gullick, M. M., \& Booth, J. R. (2014). Individual differences in crossmodal brain activity predict arcuate fasciculus connectivity in developing readers. Journal of Cognitive Neuroscience, 26(7), 1331-1346

Gurler, D., Doyle, N., Walker, E., Magnotti, J., \& Beauchamp, M. (2015). A link between individual differences in multisensory speech perception and eye movements. Attention, Perception, E' Psychophysics, 77(4), 1333-1341.

Hahn, N., Foxe, J. J., \& Molholm, S. (2014). Impairments of multisensory integration and cross-sensory learning as pathways to dyslexia. Neuroscience $\mathcal{E}$ Biobehavioral Reviews, 47, 384-392.

Hairston, W. D., Burdette, J. H., Flowers, D. L., Wood, F. B., \& Wallace, M. T. (2005). Altered temporal profile of visual-auditory multisensory interactions in dyslexia. Experimental Brain Research, 166(3-4), 474-480.

Hasher, L., Zacks, R. T., \& May, C. P. (1999). Inhibitory control, circadian arousal, and age. In D. Gopher, \& A. Koriat (Eds.), Attention \& performance, XVII, cognitive regulation of performance: Interaction of theory and application (pp. 653-675). Cambridge, MA: MIT Press. 
Hayes, E. A., Tiippana, K., Nicol, T. G., Sams, M., \& Kraus, N. (2003). Integration of heard and seen speech: A factor in learning disabilities in children. Neuroscience Letters, 351(1), 46-50.

Høien, T., Lundberg, I., Stanovich, K. E., \& Bjaalid, I. K. (1995). Components of phonological awareness. Reading and Writing, 7(2), 171-188.

Hulme, C., Goetz, K., Gooch, D., Adams, J., \& Snowling, M. J. (2007). Paired-associate learning, phoneme awareness, and learning to read. Journal of Experimental Child Psychology, 96(2), 150-166.

Jesse, A., \& Janse, E. (2012). Audiovisual benefit for recognition of speech presented with single-talker noise in older listeners. Language and Cognitive Processes, 27(7-8), 1167-1191.

Jesse, A., Vrignaud, N., Cohen, M. A., \& Massaro, D. W. (2000). The processing of information from multiple sources in simultaneous interpreting. Interpreting, 5(2), 95-115.

Jones, M. W., Branigan, H. P., \& Kelly, M. L. (2009). Dyslexic and nondyslexic reading fluency: Rapid automatized naming and the importance of continuous lists. Psychonomic Bulletin \& Review, 16(3), 567-572.

Kast, M., Bezzola, L., Jäncke, L., \& Meyer, M. (2011). Multi-and unisensory decoding of words and nonwords result in differential brain responses in dyslexic and nondyslexic adults. Brain and Language, 119(3), 136-148.

Kirby, J. R., Parrila, R. K., \& Pfeiffer, S. L. (2003). Naming speed and phonological awareness as predictors of reading development. Journal of Educational Psychology, 95(3), 453.

Kirby, J. R., Desrochers, A., Roth, L., \& Lai, S. S. (2008). Longitudinal predictors of word reading development. Canadian Psychology, 49(2), 103

Kirby, J. R., Georgiou, G. K., Martinussen, R., \& Parrila, R. (2010). Naming speed and reading: From prediction to instruction. Reading Research Quarterly, 45(3), 341-362.

Krause, S., \& Moore, E. J. (1997). Effects of cognitive flexibility and phonemic awareness training on kindergarten and first-grade students' phonemic awareness, cognitive flexibility, reading, and spelling ability. (Paper presented at the annual meeting of the American Education Research Association, Chicago).

Kroll, J. F., \& Potter, M. C. (1984). Recognizing words, pictures, and concepts: A comparison of lexical, object, and reality decisions. Journal of Verbal Learning and Verba Behavior, 23(1), 39-66.

Kronschnabel, J., Brem, S., Maurer, U., \& Brandeis, D. (2014). The level of audiovisual print-speech integration deficits in dyslexia. Neuropsychologia, 62, 245-261.

Kyle, F. E., \& Harris, M. (2010). Predictors of reading development in deaf children: A 3 year longitudinal study. Journal of Experimental Child Psychology, 107(3), 229-243.

Laasonen, M., Service, E., \& Virsu, V. (2002a). Audiovisual temporal order and processing acuity in developmentally dyslexic young adults. Brain and Language, 80(3), 340-354.

Laasonen, M., Lahti-Nuuttila, P., \& Virsu, V. (2002b). Developmentally impaired processing speed decreases more than normally with age. Neuroreport, 13(9), 1111-1113.

Leinonen, S., Müller, K., Leppänen, P. H., Aro, M., Ahonen, T., \& Lyytinen, H. (2001). Heterogeneity in adult dyslexic readers: Relating processing skills to the speed and accuracy of oral text reading. Reading and Writing, 14(3-4), 265-296.

Lyon, G. R., Shaywitz, S. E., \& Shaywitz, B. A. (2003). A definition of dyslexia. Annals of Dyslexia, 53(1), 1-14.

Lyxell, B., \& Rönnberg, J. (1989). Information-processing skill and speech-reading. British Journal of Audiology, 23(4), 339-347.

Lyxell, B., \& Rönnberg, J. (1993). The effects of background noise and working memory capacity on speechreading performance. Scandinavian Audiology, 22(2), 67-70.

MacLeod, A., \& Summerfield, Q. (1987). Quantifying the contribution of vision to speech perception in noise. British Journal of Audiology, 21(2), 131-141.

MacSweeney, M., Brammer, M. J., Waters, D., \& Goswami, U. (2009). Enhanced activation of the left inferior frontal gyrus in deaf and dyslexic adults during rhyming. Brain, 132(7), 1928-1940.

Manis, F. R., Doi, L. M., \& Bhadha, B. (2000). Naming speed, phonological awareness, and orthographic knowledge in second graders. Journal of Learning Disabilities, 33(4) 325-333.

Mayringer, H., \& Wimmer, H. (2000). Pseudoname learning by German-speaking children with dyslexia: Evidence for a phonological learning deficit. Journal of Experimental Child Psychology, 75(2), 116-133.

McGurk, H., \& MacDonald, J. (1976). Hearing lips and seeing voices. Science, 264, 746-748.

Melby-Lervåg, M., Lyster, S. A. H., \& Hulme, C. (2012). Phonological skills and their role in learning to read: a meta-analytic review. Psychological Bulletin, 138(2), 322.

Messbauer, V. C., \& de Jong, P. F. (2003). Word, nonword, and visual paired associate learning in Dutch dyslexic children. Journal of Experimental Child Psychology, 84(2), 77-96.

Miller, L. M., \& D'Esposito, M. (2005). Perceptual fusion and stimulus coincidence in the cross-modal integration of speech. The Journal of Neuroscience, 25(25), 5884-5893.

Mittag, M., Thesleff, P., Laasonen, M., \& Kujala, T. (2013). The neurophysiological basis of the integration of written and heard syllables in dyslexic adults. Clinical Neurophysiology, 124(2), 315-326.

Mohammed, T., Campbell, R., Macsweeney, M., Barry, F., \& Coleman, M. (2006). Speechreading and its association with reading among deaf, hearing and dyslexic individuals. Clinical Linguistics \& Phonetics, 20(7-8), 621-630.

Müller, K., \& Brady, S. (2001). Correlates of early reading performance in a transparent orthography. Reading and Writing, 14(7-8), 757-799.

Nath, A. R., \& Beauchamp, M. S. (2012). A neural basis for interindividual differences in the McGurk effect, a multisensory speech illusion. Neurolmage, 59(1), 781-787.

Öney, B., \& Durgunoğlu, A. Y. (1997). Beginning to read in Turkish: A phonologically transparent orthography. Applied PsychoLinguistics, 18(01), 1-15

Park, H., \& Lombardino, L. J. (2013). Relationships among cognitive deficits and component skills of reading in younger and older students with developmental dyslexia. Research in Developmental Disabilities, 34(9), 2946-2958.

Pearson (2012). WAIS-IN-NL: Psychometriche eigenschappen, deel 2 van 3. Pearson White Paper. Retrieved from: https://www.pearsonclinical.nl/media/whitepapers/ Whitepaper_WAIS-IV-NL_deel_2.pdf
Pekkola, J., Laasonen, M., Ojanen, V., Autti, T., Jääskeläinen, I. P., Kujala, T., \& Sams, M. (2006). Perception of matching and conflicting audiovisual speech in dyslexic and fluent readers: An fMRI study at 3 T. Neuroimage, 29(3), 797-807.

Pennington, B. F. (2006). From single to multiple deficit models of developmental disorders. Cognition, 101(2), 385-413.

Pennington, B. F., \& Bishop, D. V. (2009). Relations among speech, language, and reading disorders. Annual Review of Psychology, 60, 283-306.

Pennington, B. F., Cardoso-Martins, C., Green, P. A., \& Lefly, D. L. (2001). Comparing the phonological and double deficit hypotheses for developmental dyslexia. Reading and Writing, 14(7-8), 707-755

Pennington, B. F., Santerre-Lemmon, L., Rosenberg, J., MacDonald, B., Boada, R., Friend, A., .. Olson, R. K. (2012). Individual prediction of dyslexia by single versus multiple deficit models. Journal of Abnormal Psychology, 121(1), 212.

Ramirez, J., \& Mann, V. (2005). Using auditory-visual speech to probe the basis of noiseimpaired consonant-vowel perception in dyslexia and auditory neuropathy. The Journal of the Acoustical Society of America, 118(2), 1122-1133.

Ramus, F. (2003). Developmental dyslexia: Specific phonological deficit or general sensorimotor dysfunction? Current Opinion in Neurobiology, 13(2), 212-218.

Ramus, F., Rosen, S., Dakin, S. C., Day, B. L., Castellote, J. M., White, S., \& Frith, U. (2003). Theories of developmental dyslexia: Insights from a multiple case study of dyslexic adults. Brain, 126(4), 841-865.

Reitan, R. M. (1958). Validity of the Trail Making Test as an indicator of organic brain damage. Perceptual and Motor Skills, 8(3), 271-276.

Reynolds, C. R., \& Shaywitz, S. E. (2009). Response to intervention: Prevention and remediation, perhaps. Diagnosis, no. Child Development Perspectives, 3(1), 44-47.

Rispens, J., \& Baker, A. (2012). Nonword repetition: The relative contributions of phonological short-term memory and phonological representations in children with language and reading impairment. Journal of Speech, Language, and Hearing Research, $55(3), 683-694$.

Rosen, S. (2003). Auditory processing in dyslexia and specific language impairment: Is there a deficit? What is its nature? Does it explain anything? Journal of Phonetics, 31(3), 509-527.

Sanchez-Cubillo, I., Perianez, J. A., Adrover-Roig, D., Rodriguez-Sanchez, J. M., Rios-Lago, M., Tirapu, J. E. E. A., \& Barcelo, F. (2009). Construct validity of the Trail Making Test: role of task-switching, working memory, inhibition/interference control, and visuomotor abilities. Journal of the International Neuropsychological Society, 15(3), 438.

Schatschneider, C., Carlson, C. D., Francis, D. J., Foorman, B. R., \& Fletcher, J. M. (2002). Relationship of rapid automatized naming and phonological awareness in early reading development implications for the double-deficit hypothesis. Journal of Learning Disabilities, 35(3), 245-256.

Simon, J. R. (1990). The effects of an irrelevant directional cue on human information processing: The "Stroop effect" versus the "Simon effect.". Acta Psychologica, 73, 159-170.

Snowling, M. J. (2000). Dyslexia. Oxford: Blackwell publishing.

Stanovich, K. E. (1988). Explaining the differences between the dyslexic and the gardenvariety poor reader: The phonological-core variable-difference model. Journal of Learning Disabilities, 21, 590-604.

Stanovich, K. E., \& Siegel, L. S. (1994). Phenotypic performance profile of children with reading disabilities: A regression-based test of the phonological-core variable-difference model. Journal of Educational Psychology, 86(1), 24.

Stevenson, R. A., Zemtsov, R. K., \& Wallace, M. T. (2012). Individual differences in the multisensory temporal binding window predict susceptibility to audiovisual illusions. Journal of Experimental Psychology: Human Perception and Performance, 38(6), 1517.

Stoodley, C. J., \& Stein, J. F. (2006). A processing speed deficit in dyslexic adults? Evidence from a peg-moving task. Neuroscience Letters, 399(3), 264-267.

Strand, J., Cooperman, A., Rowe, J., \& Simenstad, A. (2014). Individual differences in susceptibility to the McGurk effect: Links with lipreading and detecting audiovisual incongruity. Journal of Speech, Language, and Hearing Research, 57(6), 2322-2331.

Summerfield, Q. (1992). Lipreading and audio-visual speech perception. Philosophical Transactions of the Royal Society, Serie B: Biological Sciences, 335(1273), 71-78.

Swanson, H. L., Howard, C. B., \& Saez, L. (2006). Do different components of working memory underlie different subgroups of reading disabilities? Journal of Learning Disabilities, 39(3), 252-269.

Swanson, H. L., Zheng, X., \& Jerman, O. (2009). Working memory, short-term memory, and reading disabilities: A selective meta-analysis of the literature. Journal of Learning Disabilities, 42(3), 260-287.

Tabachnick, B. G., \& Fidell, L. S. (2012). Using multivariate statistics (6th ed.). New Jersey: Allyn \& Bacon.

Tiippana, K. (2014). What is the McGurk effect? Frontiers in Psychology, 5(725), 1-3.

Torgesen, J. K., Wagner, R. K., \& Rashotte, C. A. (1994). Longitudinal studies of phonological processing and reading. Journal of Learning Disabilities, 27, 276-286.

van Bergen, E., de Jong, P. F., Maassen, B., \& van der Leij, A. (2014). The effect of parents' literacy skills and children's preliteracy skills on the risk of dyslexia. Journal of Abnormal Child Psychology, 42(7), 1187-1200.

van den Bos, K. P. (1998). IQ phonological awareness and continuous-naming speed related to Dutch poor decoding children's performance on two word identification tests. Dyslexia, 4(2), 73-89.

van Linden, S., \& Vroomen, J. (2008). Audiovisual speech recalibration in children. Journal of Child Language, 35(4), 809-822.

van Son, N., Huiskamp, T. M., Bosman, A. J., \& Smoorenburg, G. F. (1994). Viseme classifications of Dutch consonants and vowels. The Journal of the Acoustical Society of America, 96(3), 1341-1355.

van Wassenhove, V., Grant, K. W., \& Poeppel, D. (2007). Temporal window of integration in auditory-visual speech perception. Neuropsychologia, 45(3), 598-607.

Vellutino, F. R., Scanlon, D. M., \& Spearing, D. (1995). Semantic and phonological coding in poor and normal readers. Journal of Experimental Child Psychology, 59(1), 76-123. 
Vellutino, F. R., Fletcher, J. M., Snowling, M. J., \& Scanlon, D. M. (2004). Specific reading disability (dyslexia): What have we learned in the past four decades? Journal of Child Psychology and Psychiatry, 45(1), 2-40.

Wagner, R. K., \& Torgesen, J. K. (1987). The nature of phonological processing and its causal role in the acquisition of reading skills. Psychological Bulletin, 101(2), 192

Wallace, M. T., \& Stevenson, R. A. (2014). The construct of the multisensory temporal integration window and its dysregulation in developmental disabilities. Neuropsychologia, 64, 105-123.

Wechsler, D. (2012). WAIS-IV-NL, afname en scoringshandleiding. Amsterdam: Pearson Assessment and Information BV.

Widmann, A., Schröger, E., Tervaniemi, M., Pakarinen, S., \& Kujala, T. (2012). Mapping symbols to sounds: Electrophysiological correlates of the impaired reading process in dyslexia. Frontiers in Psychology, 3, 60.
Wimmer, H., Landerl, K., Linortner, R., \& Hummer, P. (1991). The relationship of phonemic awareness to reading acquisition: More consequence than precondition but still important. Cognition, 40(3), 219-249.

Wolf, M., Bowers, P. G., \& Biddle, K. (2000). Naming-speed processes, timing, and reading a conceptual review. Journal of Learning Disabilities, 33(4), 387-407.

Woll, B. (2012). Speechreading revisited. Deafness \& Education International, 14(1), $16-21$.

Žarić, G., González, G. F., Tijms, J., van der Molen, M. W., Blomert, L., \& Bonte, M. (2014) Reduced neural integration of letters and speech sounds in dyslexic children scales with individual differences in reading fluency. PloS One, 9(10).

Žarić, G., González, G. F., Tijms, J., van der Molen, M. W., Blomert, L., \& Bonte, M. (2015). Crossmodal deficit in dyslexic children: Practice affects the neural timing of letterspeech sound integration. Frontiers in Human Neuroscience, 9, 369. 